\title{
What Investigations Are Ordered in Patients with First-episode Psychosis?
}

\author{
Allan Shefrin M.D. (PGY2) \\ Derek Puddester M.D. \\ Puddester@cheo.on.ca \\ Stephanie Greenham Ph.D. \\ Lise Bisnaire Ph.D. \\ Hazen Gandy M.D.
}

Follow this and additional works at: https://jdc.jefferson.edu/jeffjpsychiatry

Part of the Psychiatry Commons

Let us know how access to this document benefits you

\section{Recommended Citation}

Shefrin, Allan M.D. (PGY2); Puddester, Derek M.D.; Greenham, Stephanie Ph.D.; Bisnaire, Lise Ph.D.; and Gandy, Hazen M.D. (2006) "What Investigations Are Ordered in Patients with First-episode Psychosis?," Jefferson Journal of Psychiatry. Vol. 20 : Iss. 1 , Article 2.

DOI: https://doi.org/10.29046/JJP.020.1.001

Available at: https://jdc.jefferson.edu/jeffjpsychiatry/vol20/iss1/2

This Article is brought to you for free and open access by the Jefferson Digital Commons. The Jefferson Digital Commons is a service of Thomas Jefferson University's Center for Teaching and Learning (CTL). The Commons is a showcase for Jefferson books and journals, peer-reviewed scholarly publications, unique historical collections from the University archives, and teaching tools. The Jefferson Digital Commons allows researchers and interested readers anywhere in the world to learn about and keep up to date with Jefferson scholarship. This article has been accepted for inclusion in Jefferson Journal of Psychiatry by an authorized administrator of the Jefferson Digital Commons. For more information, please contact: JeffersonDigitalCommons@jefferson.edu. 


\section{What Investigations Are Ordered in Patients with First-episode Psychosis?}

Allan Shefrin, M.D. (PGY2), Derek Puddester, M.D., Stephanie Greenham, Ph.D., Lise Bisnaire, Ph.D., Hazen Gandy, M.D.

\section{ABSTRACT}

Psychiatrists are often left with the dilemma of which investigations to order in adolescents presenting with a first episode of psychosis. Blood work, urine studies, and neuroimaging studies were tracked in 13 adolescents admitted with a diagnosis of first-episode psychosis over a 13-month period to the Children's Hospital of Eastern Ontario. Variation was found in the amount of investigation ordered: $85 \%$ of patients received a drug screen; $54 \%$ a CT scan; $8 \%$ an MRI; 92\% a CBC with differential; 92\% electrolytes. Abnormalities of CT scans were detected in 2 patients (29\%); in neither case did the result lead to a diagnosis of brain-lesion-related psychosis, nor did it affect the clinical care of the patient. This study highlights the need to develop clinical practice-guidelines for the workup of first-episode psychosis in adolescents.

First-episode psychosis has received considerable attention in both the pediatric and adult literature. One area of ongoing research is the degree to which children and adolescents require investigations to rule in or rule out non-psychiatric disease. According to the Diagnostic and Statistical Manual of Mental Disorders $4^{\text {th }}$ Edition Text Revision (DSM-IV-TR), the diagnosis of schizophrenia and other psychotic illnesses require that criteria be met: where "the disturbance is not due to the direct physiological effects of a substance (e.g., of abuse or a medication) or a general medical condition"(1). Yet, in spite of these essential criteria, a standardized workup for first episode psychosis in children and youth is difficult to find.

Psychiatry associations and textbooks differ in their recommendations and often leave the decision to perform a test at the discretion of the attending physician. A summary of different guidelines can be found in Table 1. 
Table 1: Summary of various guidelines for the investigation of patients with first episode psychosis

\begin{tabular}{|c|c|}
\hline Source & Suggested V \\
\hline Kaplan and Sadock(2) & $\begin{array}{l}\text { - Do: complete history and physical exam, urine toxicology screen, } \\
\text { CBC, general chemistry screen, urinalysis } \\
\text { - Consider: pregnancy test, ECG, MRI, CT, EEG }\end{array}$ \\
\hline Rutter and Taylor(3) & $\begin{array}{l}\text { Do: CBC, ESR, electrolytes, renal function tests, glucose, calcium, } \\
\text { magnesium, phosphate, liver enzymes, albumin, TSH, urinalysis, urine } \\
\text { toxicology screen } \\
\text { - Consider: neuroimaging }\end{array}$ \\
\hline Wiener(4) & $\begin{array}{l}\text { - Do: sexually transmitted disease screen } \\
\text { - } \quad \text { Consider other investigations as guided by history and physical exam }\end{array}$ \\
\hline $\begin{array}{l}\text { American Psychiatric } \\
\text { Association(5) }\end{array}$ & $\begin{array}{l}\text { Do: history and physical exam, thyroid function tests, renal function } \\
\text { tests, liver function tests, pregnancy screen, toxicology screen, syphilis } \\
\text { screen } \\
\text { - Consider: screening for HIV and hepatitis C, EEG/CT/MRI if indicated } \\
\text { (new onset psychosis and atypical psychosis) }\end{array}$ \\
\hline $\begin{array}{l}\text { American Association of } \\
\text { Child and Adolescent } \\
\text { Psychiatrists (AACAP)(6, 7) }\end{array}$ & $\begin{array}{l}\text { Consider: CBC, chemistry, thyroid function tests, urinalysis, toxicology } \\
\text { screen, infectious disease screens (if at risk) })^{+} \text {, chromosomal analysis (if } \\
\text { suggestive of developmental syndrome), neuroimaging (if evidence of } \\
\text { neurologic dysfunction) }\end{array}$ \\
\hline \multicolumn{2}{|c|}{$\begin{array}{l}\text { CBC - complete blood count / ECG - electrocardiogram } \\
\text { MRI - magnetic resonance imaging / CT - computed Tomography } \\
\text { EEG - electroencephalogram / ESR - erythrocyte sedimentation rate } \\
\text { TSH - thyroid stimulating hormone } \\
+ \text { - high risk groups include: all adolescents with psychiatric symptoms; high risk adolescents (e.g.: runaways, } \\
\text { delinquents, children of substance abusers); adolescents with changes in mental status or performance; adolescents } \\
\text { with acute behavior changes; adolescents with recurrent accidents or unexplained somatic symptoms; adolescents } \\
\text { for whom abstinence is to be monitored }\end{array}$} \\
\hline
\end{tabular}

There is much debate in the literature regarding the inclusion of neuroimaging in the standard work-up of children with first-episode psychosis. Some advocate a rule-in approach while others prefer a rule-out approach. The AACAP suggests that the use of CT and MRI be reserved for ruling out intracranial disease when suspected, and that they are of very low positive yield in the absence of clinical findings.(6, 7) Adams et al. conclude that routine endocrine and neuroimaging screening tests in first-onset adolescent psychosis are of little diagnostic utility and are not cost effective (8). They recommend that investigations be reserved for cases with symptoms suggestive of non-psychiatric pathology. Larson et al. concluded that CT scans should be used to rule in intracranial pathology as it has low yield in assisting clinical decisions in the absence of focal neurologic deficit (9). 
Yet a growing body of evidence suggests the potential value of neuroimaging for patients with first-episode psychosis. Various CT studies in adolescents and adults have found that patients with schizophrenia and other psychotic disorders exhibit ventricular enlargement, cortical atrophy, and cerebrospinal-fluid (CSF) circulation-disturbances (10-16). Magnetic resonance imaging is increasingly being used as a diagnostic and research tool in psychiatric illness. Various studies report gray matter deficits, increased CSF volume, decreased cerebral volume, thalamic abnormalities, and diminished size of the fusiform gyrus associated with psychosis (15-22). Jacobsen and Rapoport suggest that CT and MRI changes are not static but are affected by the duration or severity of illness and the modality and success of treatment (21).

Moreno et al. note that the interpretation of pediatric neuroimaging studies is difficult, owing to the variability of normal results secondary to age and body-size. They also note that diagnostic testing may be required in assisting patients and their families in gaining access to social and financial services (23).

Finally, many psychiatrists have informally reported cases of first-episode psychosis that have later been determined to result from a general medical condition (for example, intracranial tumor, developmental structural anomalies, metabolic disease, genetic disease, or seizure disorder). Thus, some psychiatrists advocate that a thorough workup should be done from a quality and risk management perspective. But few data, to date, support this perspective.

\section{METHODS}

All psychiatry inpatients admitted for the 13 months from October 1, 2000 to October 31, 2001 were eligible for entry into the study database. Patients or their legal guardians (for those under 16 years of age) gave consent for their inclusion. The Research Ethics Board of the Children's Hospital of Eastern Ontario (CHEO) approved the study.

Patients were excluded from this study if they had a seizure disorder, diabetes, anemia, migraine, endocrine disorder, or vitamin B12 deficiency. Patients readmitted to service were also excluded.

This process identified 174 patients, of which 13 presented with a primary diagnosis of psychosis. The remainder had mood or anxiety disorders. There were many more cases of psychosis, but they either presented with mood symptoms, or the psychosis was not evident at the time of admission. The 13 diagnosed with first-episode psychosis were age 14 to 17 years; 9 were male and 4 were female. 
Research assistants reviewed all inpatient charts and records and biological data was entered into the study database. Laboratory results were collected for patients and were divided based on whether tests were normal, abnormal, abnormally high, abnormally low and not ordered. Percentages of normal and abnormal results were calculated based on the number of tests ordered. With the exception of the CBC and urinalysis, which are required by the hospital for all admitted patients, tests are ordered at the discretion of the admitting psychiatrist.

\section{RESULTS}

A neuroimaging study was ordered in $62 \%$ of patients (Table 2). Of these 8 studies, an abnormality was detected in 2.

Table 2: Results of neuroimaging studies for children and adolescents admitted to the Children's Hospital of Eastern Ontario with a diagnosis of first-episode psychosis

\begin{tabular}{|l|l|l|l|}
\hline Test & Norm & Abnorm & Not Ordered \\
\hline CT Head & 5 & 2 & 6 \\
\hline MRI & 1 & 0 & 12 \\
\hline EEG & 8 & 0 & 5 \\
\hline
\end{tabular}

With respect to blood tests and urine toxicology, 92\% of the patients were investigated (Tables 3 and 4). 
Table 3: Laboratory investigations performed in 13 patients admitted to the Children's Hospital of Eastern Ontario with a diagnosis of first-episode psychosis

\begin{tabular}{|l|l|l|l|l|}
\hline Test & Normal & Abnormal high & Abnormal low & Not Ordered \\
\hline WBC & 8 & 2 & 2 & 1 \\
\hline Neutrophils & 9 & 2 & 1 & 1 \\
\hline Hemoglobin & 10 & 1 & 1 & 1 \\
\hline Platelets & 12 & 0 & 0 & 1 \\
\hline TSH & 11 & 0 & 0 & 2 \\
\hline AST & 7 & 0 & 0 & 6 \\
\hline ALT & 8 & 1 & 3 & 1 \\
\hline Sodium & 12 & 0 & 0 & 1 \\
\hline Chloride & 12 & 0 & 0 & 1 \\
\hline Potassium & 12 & 0 & 0 & 1 \\
\hline Calcium & 0 & 0 & 0 & 13 \\
\hline Magnesium & 5 & 0 & 0 & 8 \\
\hline Phosphate & 5 & 0 & 0 & 8 \\
\hline Glucose & 5 & 1 & 2 & 5 \\
\hline Urea & 8 & 0 & 2 & 3 \\
\hline Creatinine & 10 & 1 & 0 & 2 \\
\hline
\end{tabular}

Table 4: Toxin and drug of abuse testing in a sample of children and adolescents admitted to the Children's Hospital of Eastern Ontario with a diagnosis of first-episode psychosis

\begin{tabular}{|l|l|l|l|}
\hline Toxin Screened & Negative & Positive & Not ordered \\
\hline Acetaminophen & 0 & 2 & 11 \\
\hline Salicylates & 0 & 2 & 11 \\
\hline Ethanol & 1 & 0 & 12 \\
\hline Phencyclidine & 11 & 0 & 2 \\
\hline Benzodiazepines & 8 & 3 & 2 \\
\hline Cocaine & 11 & 0 & 2 \\
\hline Amphetamines & 10 & 1 & 2 \\
\hline Tetrahydrocannabinol & 7 & 4 & 2 \\
\hline Opiates & 10 & 1 & 2 \\
\hline Barbiturates & 11 & 0 & 2 \\
\hline
\end{tabular}

No patients were tested for sexually transmitted diseases. Two of the four female patients were tested for pregnancy. Both tests were negative. 


\section{DISCUSSION}

There is considerable variation in investigations ordered by admitting psychiatrists for the workup of first-episode psychosis. Psychiatrists, overall, at the Children's Hospital of Eastern Ontario tended to order more tests than are recommended by some authors, but vary greatly among themselves: 85\% of patients received a drug screen, $54 \%$ received a CT scan, $8 \%$ received an MRI and $92 \%$ received a CBC with differential and electrolytes. The variability may result from the lack of a clear practice guideline from an authoritative source or the risks, both medical and legal, of missing an alternative diagnosis. Some sources suggest the variability results from the lack of confidence psychiatrists have in their medical knowledge (8).

Attention should be given to differentiating which tests should be used for screening purposes and which tests for diagnostic purposes. In our study, 29\% of patients who received a CT scan of the head had an abnormal result. One patient had a questionable mass in the right frontal lobe (not confirmed by MRI). The other abnormal CT was suggestive of slightly large ventricles; MRI investigation was not done on this patient during the study period. Neither abnormal CT result impacted on the patient's diagnosis or treatment. As MRI becomes more accessible and affordable in Canada and a better understanding of the relationship between clinical and neuroimaging findings is attained, MRI may prove to be of utility in the clinical investigation of psychosis. This is also true of newer modalities such as positron emission tomography and single photon emission tomography.

It is widely understood that substance use is common in individuals with psychosis. Our study found that a considerable percentage of our subjects had clinically detectable levels of substances in their bodies. Of greater concern, however, is that $15 \%$ of patients were not screened for any substances at all, and $92 \%$ were not screened for ethanol. Given that substances can cause psychosis, affect its prognosis, and represent a major comorbidity, it seems essential that these particular investigations be considered in all patients with a psychotic presentation.

Limitations of this study are clear. Our sample size is small, and correlative and causative conclusions cannot be drawn. We did not capture why certain studies were ordered in some patients and not others. Finally, the study was limited to biological investigations, and does not include the potentially valuable contribution of psychological and other evaluations.

Based on the results of this study, we can conclude that there is large variability in the ordering of investigations at CHEO for adolescents with first-episode psychosis. The findings of abnormal CT scans correlate with previous studies. Correlative and causative conclusions cannot be drawn with such a small sample

Jefferson Journal of Psychiatry, Volume 20, Number 1

ISSN 1935-0783

(C) 2006 by the authors

On the Web: jdc.jefferson.edu/jeffjpsychiatry 
size. Therefore, more studies are needed to better standardize admission investigations and determine clinical correlations with laboratory findings. This will help guide further investigations such as cost/benefit analysis and monitoring of disease and treatment response.

\section{SOURCE INFORMATION}

From the University of Calgary (AS), the Department of Psychiatry, University of Ottawa (DP, HG), and the Mental Health Patient Service Unit, Children's Hospital of Eastern Ontario (SG, LB). The authors thank the Psychiatry Associates of the Children's Hospital of Eastern Ontario for funding the study, and wish to acknowledge Juliette Oleynik for her assistance with the manuscript. Direct inquiries to Dr. Puddester at puddester@cheo.on.ca

\section{REFERENCES}

1. American Psychiatric Association (2000). Diagnostic and Statistical Manual of Mental Disorders, 4th Edition-Text Revision. Washington, D.C.: American Psychiatric Association Publishing Group

2. Kaplan BJ, Sadock VA (2002). Kaplan and Sadock's Textbook of Psychiatry: Behavioral Sciences/Clinical Psychiatry. Philadelphia: Lippincott, Williams and Wilkins

3. Rutter M, Taylor E (2002). Child and Adolescent Psychiatry. Oxford: Blackwell

4. Wiener JM (1997). Textbook of Child and Adolescent Psychiatry. Washington D.C.: American Psychiatric Press

5. Lehman AF, Lieberman JA, Dixon LB, McGlashan TH, Miller AL, Perkins DO, Kreyenbuhl J (2004), ed. American Psychiatric Association: Practice Guideline for the Treatment of Patients with Schizophrenia. Arlington, VA: American Psychiatric Association Publishing Group

6. Zametkin AJ, Ernst M, Silver R. Laboratory and Diagnostic Testing in Child and Adolescent Psychiatry: A Review of the Past Ten Years. J Am Acad Child Adoles Psychiatry 1998; 37: 464-72 
7. McClellan J, Werry J, Bernet W, Arnold V, Beitchman J, Benson RS, Bukstein A, Kinlan J, Rue D, Shaw J, eds. Practice parameter for the assessment and treatment of children and adolescents with schizophrenia. J Am Acad Child Adoles Psychiatry 2001; 40(7 Supplement):4S-23S

8. Adams M, Kutcher S, Antoniw E, Bird D. Diagnostic Utility of Endocrine and Neuroimaging Screening Tests in First-onset Adolescent Psychosis. J Am Acad Child Adoles Psychiatry 1996; 35:67-73

9. Larson EB, Mack LA, Watts B, Cromwell LD. Computed Tomography in Patients With Psychiatric Illnesses: Advantages of a Rule-in Approach. Ann Intern Med 1981; 95:360-4

10. Schulz SC, Koller MM, Kishore PR, Hamer RM, Gehl JJ, Friedel RO. Ventricular Enlargement in Teenage Patients with Schizophrenia Spectrum Disorder. Am J Psychiatry 1983; 140:1592-5

11. Gewirtz G, Squires-Wheeler E, Sharif Z, Honer WG. Results of Computerized Tomography During First Admission for Psychosis. Brit J Psychiatry 1994; 164:789-95

12. Weinberger DR, DeLisi LE, Perman GP, Targum S, Wyatt RJ. Computed Tomography in Schizophreniform Disorder and Other Acute Psychiatric Disorders. Arch Gen Psychiatry 1982; 29:778-83

13. Nyback H, Wiesel FA, Berggren BM, Hindmarsh T. Computed Tomography of the Brain in Patients With Acute Psychosis and in Healthy Volunteers. Acta Psych Scand 1982; 65:403-14

14. MacDonald HL, Best JK. The Scottish First Episode Schizophrenia Study: VI. Computerised Tomography Brain Scans in Patients and Controls. Brit J Psychiatry 1989; 154:492-8

15. Hendren RL, De Backer I, Pandina GH. Review of Neuroimaging studies of child and adolescent psychiatric disorders from the past 10 year. J Am Acad Child Adoles Psychiatry 2000; 39(7):815-28

16. Peterson BS. Neuroimaging in Child and Adolescent Neuropsychiatric Disorders. J Am Acad Child Adoles Psychiatry 1995; 34(12):1560-76 
17. Zipursky RB, Lambe EK, Kapur S, Mikulis DJ. Cerebral Gray Matter Volume Deficits in First Episode Psychosis. Arch Gen Psychiatry 1998; 55:540-6

18. Frazier JA, Giedd JN, Hamburger SD, Albus KE, Kaysen D, Vaituzis AC, Rajapakse JC, Lenane MC, McKenna K, Jacobsen LK, Gordon CT, Breier A, Rapoport JL. Brain Anatomic Magnetic Resonance Imaging in Childhood-onset Schizophrenia. Arch Gen Psychiatry 1996; 53:617-24

19. Ettinger U, Chitnis XA, Kumari V, Fannon DG, Sumich AL, O'ceallaigh S, Doku V, Sharma T. Magnetic Resonance Imaging of the Thalamus in First-episode Psychosis. Am J Psychiatry 2001; 158:116-8

20. Lee CU, Shenton ME, Salisbury DF, Kasaim K, Onitsuka T, Dickey CC, Yurgelun-Todd D, Kikinis R, Jolesz FA, McCarley RW. Fusiform Gyrus Volume Reduction in First-episode Schizophrenia. Arch Gen Psychiatry 2002; 59:775-81

21. Wood SJ, Velakoulis D, Smith DJ, Bond D, Stuart GW, McGorry PD, Brewer WJ, Bridle N, Eritaia J, Desmond P, Singh B, Copolov D, Pantelis C. A Longitudinal Study of Hippocampal Volume in First-episode Psychosis and Chronic Schizophrenia. Schizophr Research 2001; 52:37-46

22. Jacobsen LK, Rapoport JL. Research Update: Childhood-onset Schizophrenia Implications fot Clinical and Neurobiological Research. J Child Psychol and Psychiatry 1998; 39:101-13

23. Moreno D, Burdalo M, Reig S, Parellada M, Ala AZ, Desco M, BacaBaldomero E, Arango C. Structural neuroimaging in adolescents with first episode psychosis. J Am Acad Child Adoles Psychiatry 2005; 44: 1151-7 